\begin{tabular}{|l|l|l||}
\hline \multicolumn{2}{|c|}{ PublisherInfo } \\
\hline \hline PublisherName & $:$ & BioMed Central \\
\hline \hline PublisherLocation & $:$ & London \\
\hline \hline PublisherImprintName & $:$ & BioMed Central \\
\hline \hline
\end{tabular}

\title{
Global analysis of chloroplast proteins
}

\begin{tabular}{|l|l|l||}
\hline \multicolumn{2}{|c|}{ ArticleInfo } \\
\hline \hline ArticleID & $:$ & 3625 \\
\hline \hline ArticleDOI & $:$ & $10.1186 /$ gb-2000-1-2-reports0048 \\
\hline \hline ArticleCitationID & $:$ & reports0048 \\
\hline \hline ArticleSequenceNumber & $:$ & 22 \\
\hline \hline ArticleCategory & $:$ & Paper report \\
\hline \hline ArticleFirstPage & $:$ & 1 \\
\hline \hline ArticleLastPage & $:$ & 4 \\
\hline \hline & & RegistrationDate : 2000-4-30 \\
ArticleHistory & $:$ & Received \\
\hline \hline ArticleCopyright & $:$ & BioMed Central Ltd2000-4-30 \\
\hline \hline ArticleGrants & $:$ & \\
\hline \hline
\end{tabular}




\begin{tabular}{|l|l|l||}
\hline ArticleContext & $:$ & 130591122 \\
\hline
\end{tabular}

\section{Todd Richmond}

\section{Abstract}

Systematic analysis of the chloroplast and its photosynthetic machinery has begun, using a combination of two-dimensional gels, mass spectroscopy, protein sequencing and genome databases.

\section{Significance and context}

The chloroplast and the molecular machinery responsible for photosynthesis have been the subject of intense study for decades. Peltier et al. have taken advantage of the extraordinary amount of biochemistry that has been done on the chloroplast and the thylakoid membrane, and combined it with some cutting-edge tools to initiate a new study of chloroplast proteins and targeting sequences. They demonstrate how protein purification techniques, mass spectroscopy, protein sequencing and the everexpanding DNA and protein sequence databases can be combined in a new approach to an old problem. It has been estimated that the plant chloroplast contains between 2,000 and 5,000 proteins, although the chloroplast genome encodes only about 120 proteins. A majority of the proteins that comprise the chloroplast are therefore encoded by the nuclear genome and must be post-translationally targeted to the chloroplast. Whereas the presequences that constitute the amino-terminal transit peptides of these proteins can be predicted with some confidence, the degeneracy of these sequences precludes a PCRbased approach to identifying all chloroplast-localized proteins. Hence a proteomic approach is called for. Recent improvements in protein solubilization techniques and two-dimensional gel electrophoresis now enable the resolution of up to 2,000 proteins on a single two-dimensional gel. Using computeraided image analysis, two-dimensional gels can be aligned and protein spots of interest can be subjected to further analysis.

\section{Key results}

Peltier et al. isolated pea chloroplasts and, through a series of purification steps, isolated lumenal and peripheral thylakoid proteins. A series of two-dimensional gels, using both low $\mathrm{pH}$ and high $\mathrm{pH}$ ranges, was used to improve the resolution of the resulting two-dimensional electrophoresis maps. A total of between about 820 and 920 protein spots can be detected using these methods, which, after adjusting for protein isoforms, post-translational modifications and proteolysis, represent approximately 200 proteins. The authors used three techniques to analyze protein spots: matrix-assisted laser desorption/ionizationtime of flight (MALDI-TOF) mass spectroscopy, electrospray ionization tandem (ESI) mass 
spectroscopy and amino-terminal Edman sequencing. The initial analysis, conducted on 400 spots, consisted of an in-gel protease digestion of the proteins followed by MALDI-TOF mass spectroscopy. The list of measured peptide masses produced by this method was compared with the theoretical masses from predicted tryptic peptides for each entry in the public sequence databases. For proteins not unambiguously identified by this method, peptide sequence tags were obtained by ESI mass spectroscopy or Edman sequencing and used for homology-based searches. Peltier et al. successfully identified 61 proteins, and for 33 of these a clear function could be assigned. Of the remainder, $10 \mathrm{had}$ no known function, and for the remaining 18 proteins, no expressed sequence tags or full-length genes were identified.

The study also examined the predictive power of several programs designed to identify proteinsorting signals. The authors conclude that the PSORT and ChloroP programs are not ideal, the former being too conservative and the latter resulting in too many false positives. The lumenal transit peptides for 26 proteins were determined and found to be similar to those of signal peptides in bacteria. Peltier et al. point out several conserved features in these transit peptides, and suggest that existing programs may be adapted to allow prediction of lumenal transit peptides in a global manner with high confidence.

\section{Links}

The authors used several different programs to predict protein localization signals, including PSORT, ChloroP, and SignalP. The ProteinProspector site contains many online tools for using sequence databases in conjunction with mass spectroscopy experiments.

\section{Reporter's comments}

It is not entirely clear why the authors chose to use pea as the source of their thylakoid membranes rather than Arabidopsis, especially considering the sensitivity of the methods being used. As the authors themselves point out, a single mismatch between a pea peptide and a corresponding Arabidopsis sequence is enough to prevent a match at the 50 parts per million mass resolution cut-off being used. Although it is more difficult to isolate chloroplasts from Arabidopsis than from pea, the vast amount of Arabidopsis sequence information available should make that effort worthwhile. But pea chloroplasts have been the subject of photosynthesis research for many years and there is a surprising amount of peptide information in the public databases. The researchers were able to identify almost a third of the estimated 200 proteins and gather important data on lumenal transit peptides. Clearly this is only one of the first of many proteomics papers that we can expect. Many processes are regulated exclusively at the protein level and it is clear that this type of approach, with the ability to measure protein abundance as well as to examine post-translational modifications, will become increasingly useful. 


\title{
Table of links
}

\author{
Plant Cell
}

PSORT

ChloroP

SignalP

ProteinProspector

\section{References}

1. Peltier J-B, Friso G, Kalume D, Roepstorff P, Nilsson F, Adamska I, Wijk K van: Proteomics of the chloroplast: systematic identification and targeting analysis of lumenal and peripheral thylakoid proteins. Plant Cell. 2000, 12: 319-341. 1040-4651

This PDF file was created after publication. 